\title{
The Impact of Autocratic Leadership on Disruptive Political Behavior, Moderating the Relationship of Abusive Supervisory Behavior and Mediating the Relationship of Employee's Perception of Job Insecurity
}

\author{
Asif Hussain ${ }^{1}$, Xue Yang ${ }^{1}$, Lu Yali ${ }^{1}$, Asma Ibrahim $^{2} \&$ Samina Hussain $^{3}$ \\ ${ }^{1}$ School of Management and Economics, North China University of Water Resources and Hydropower Power, \\ Henan, China \\ ${ }^{2}$ Department of Management School of Business and Economics, University of Management and Technology, \\ Lahore, Pakistan \\ ${ }^{3}$ Punjab University College of Information Technology, Lahore, Pakistan \\ Correspondence: Lu Yali, School of Management and Economics, North China University of Water Resources and \\ Hydropower, Henan 450046, China. Tel: 86-187-3993-6530. E-mail: luyali@ncwu.edu.cn
}

Received: January 13, 2020

Accepted: May 6, 2020

Online Published: May 20, 2020

doi:10.5539/ijef.v12n6p57

URL: https://doi.org/10.5539/ijef.v12n6p57

\begin{abstract}
This study examines the impact of Autocratic leadership on Disruptive Political Behavior with the moderating effect of Abusive Supervisory Behavior and the mediating effect of Employee Perception of Job Insecurity. It examines the employee perception of job insecurity while working in an autocratic culture and the political strategies which an employee chooses to cope up with such insecurities. The data was collected through a structured questionnaire from a sample of 248 employees which include middle-level managers, front-line managers, and their employees. Pearson correlation test was used to establish the relationship between variables. Findings reveal the existence of a significant positive relationship between the variables. Result also prove that there is a significant positive moderation of abusive supervisory behavior between the relationship of autocratic leadership and employee perception of job insecurity, and shows partial significance with mediating effect of employee perception of job insecurity with the relation of autocratic leadership and disruptive political behavior. The study concludes with a discussion and future directions.
\end{abstract}

Keywords: autocratic leadership, abusive supervisory behavior, employee's perception of job insecurity and disruptive political behavior, a leadership trait, performances

\section{Background of the Study}

The telecommunication sector is one of the significant sectors in today's world reasoning the fact of its great contribution in the economic sector of Pakistan. The telecommunication sector is working highly in providing better services to their customers. To check the various practices applied in the public and private sectors both, the present research is conducted. For meeting the expected targets, the leader who is having the autocratic leadership trait, assert his dominance over his followers or subordinates by controlling their performances through threats, and pressurize them for completing the tasks. This makes the leader to adopt abusiveness towards his subordinates (Kiazad, Restubog, Zagenczyk, Kiewitz, \& Tang, 2010). This supervisory behavior inhibits perception of job insecurity in an employee (Hoel \& Cooper, 2000; McCarthy et al., 1995; Sheehan, 1996), which will ultimately affect the performance of an individual itself and the organization (De Witte, 1999; Sverke et al., 2002; De Witte et al., 2010; Vetting, 2010). Such employees who perceive insecurity, likely to react against the organization and also other individuals working in the organization (Tepper et al., 2008, 2009; Thau et al., 2009; Biron, 2010; Thau \& Mitchell, 2010).

\section{Introduction}

Taking the organizational environment into the context, the employees working in the organizations are more likely to work in that kind of environment where dictatorship and the leader's control over the subordinates exist (Cheng, Chou, Wu, Huang, \& Farh, 2004). The people work with defined rules and policies organized for better 
and enhancing performance. Usually, the organizations are echoed in the environment of the authoritative leadership style. This leadership style captures a behavior which declares a complete authority and control over the subordinates working in the organization, demanding undeniable obedience from them (Cheng, Chou, Wu, Huang, \& Farh, 2004, p. 91). For this instance, authoritarian leaders more likely to create an environment of control by originating an organizational structure by issuing rules and policies, promise to give rewards for their obedience and threaten them for punishment in a situation of non-compliance (Aryee et al., 2007). These leaders take the decisions according to their own choices and deny to take the advice from their sub-ordinates. All the directions, goals, and structure of doing the tasks are set already and the leader expects to accomplish the tasks given by them to the group members (Malik, Saleem, \& Naeem, 2016).

Instead of enhancing the performance of individuals, sometimes the authoritative power flow towards a negative way of abusiveness. When the sub-ordinate fail to follow the defined terms and conditions, then the supervisor or the boss is most likely to abuse them. Similarly, the more use of authoritative power makes the supervisor to adopt abusive behavior towards the sub-ordinates. Tepper (2000) studied abusive supervision as a sustained hostile verbal and non-verbal behavior. The supervisor's authority encourages him to adopt the abusive behavior towards the employees working in the organization if a non-compliance occurs. The leaders having the authoritarian leadership trait declare their dominance over their subordinates and control their performances through threats and pressurize them for completing the tasks (Kiazad, Restubog, Zagenczyk, Kiewitz, \& Tang, 2010). The assigned targets for completion of tasks make a leader or as supervisor to adopt abusiveness towards the followers or the sub-ordinates working in the organization

One of the studies found in the literature discussed the perception of followers regarding the abusive behavior of the supervisor negatively related to an individual's perception of ethical leadership (Kacmar, Tillman, Harris, Whitman, \& Justice, 2016). These findings highlight the behaviors of the leader which is important in perceptions of being ethical. Concerning this, abusive behavior also leaves long-term negative effects on an individual's perceptions of a leader's ethical behavior. Research suggests that if the leader improves their behaviors of abusiveness, even then it will leave long-lasting effects of their past behaviors on the followers (Chan, \& McAllister, 2014). Similarly, the excessive use of abusive behavior when faced by the employee working in the organization, inhibits the perceptual level of insecurity of losing a job in him. Taking the literature perspectives, it is clearly shown through different discussions that the authoritarian/autocratic leadership trait is linking with employee's perception of job insecurity when a leader opts for abusive behavior to fulfill the expected targets or to meet the given deadlines.

The concept of job insecurity received substantial attention to research (Sverke \& Hellgren, 2002; Vetting, 2010). Background roots of an individual's job insecurity emerged an unthreatened situation of employment (Rosenblatt \& Ruvio, 1996; Vetting, 2010). With this regard, the total number of employees perceive their job considerably as threatened (De Witte, 2005) while working under an autocratic leader who situationally adapts abusiveness towards the sub-ordinates working in the organization. Accumulated research has found a piece of evidence that employees who feel the insecurity of losing their jobs, likely to react negatively in terms of psychological well-being, work attitude and job performance (e.g., De Witte, 1999; Sverke et al., 2002). The behavior of an employee when changed, will affect the individual performance relating to the organizational performance.

Taking into the concern of an employee's political strategies for securing his job making him to choose a behavior by showing an extra concern to the supervisor by flattering him, seek help from other co-workers of the organization by telling them about such an abusive behavior of his supervisor (Biron 2010; Tepper et al., 2009; 2008; Thau et al., 2009; Thau \& Mitchell, 2010) for gaining sympathies from them or may allow him to choose a disruptive behavior by showing aggression to the boss in the form of grouping or unions of the organization and sometimes the violation of organizational policies (Freeman et al., 2001, 2005). These are some of the consequences of experiencing repeated abusive supervisory behavior which can be costly not only for organizations but also for the other targeted individuals of the organization.

The research suggested that the individuals who experienced abusive supervisory behavior usually suffers from the low job and life satisfaction with greater depression, anxiety, and are emotionally exhausted (Tepper, 2000). When an employee is emotionally exhausted by being victimized of the supervisor's abusive behavior (Tepper, 2000), the literature shows that such employees react against the organization and other individuals working in the organization, for being victimized by abusive behavior (Biron, 2010; Tepper et al., 2009, 2008; Thau et al., 2009; Thau \& Mitchell, 2010). These deviant acts opted by the employee because of abusive behavior of a supervisor which created a perception of job insecurity in an employee resulting in the adoption of disruptive political behaviors like; showing aggressive behavior to a boss in the form of grouping, unions, and violence (Freeman et al., 2001, 2005), emotional exhaustion (Tepper, 2000). 
Taking the research beneath the theoretical perspectives, when an employee perceives job insecurity due to supervisor's abusive behavior reasoning the fact of autocracy as per the organizational policies, follows the "perceived organizational politics" model which was proposed by Ferris, Russ, and Fandt in 1989. In this, an individual perceives the behavior of others which are more often related with the management of organizational policies (as per discussed as an autocratic-abusive behavior), repeatedly use the forced (autocratic) strategies on the other individuals for short-term gains (Kacmar \& Ferris, 1991) which makes an employee to perceive as his employment insecurity which renders him to move towards other behavioral patterns like; demotivation, dissatisfaction and an individual's intention to quit. When autocratic abusive behaviors are used by the supervisors hurdled an individual's interest of job leading him to perceive insecurity of losing his job.

Taking the mainstream research into the context, the constructs are making a positive linkage with each other in a way Ferris, Russ, and Fandt in 1989 gave the relationship of the constructs in the model of perceptions of organizational politics. Autocratic leadership creates a working environment bound to strict rules and policies which makes a supervisor act abusively in case of non-compliance. The employees are given rewards only if they follow-up the orders of the autocratic supervisors. The excess of abusiveness when bound-to strict rules and policies, this makes an employee perceive his job at stake. When perceiving this state, for securing one's job, some strategies opted by the employee which ultimately leads to disruptive political behaviors. This could be beneficial at the employee's side, but not for the organization.

\section{Problem Statement}

The model of "Perceived Organizational Politics" given by Ferris, Ruth \& Fandt in 1989. According to the literature, the model explains that some of the factors like job/work environment, personal influence, and organizational influence perceived by an employee as political behavior in the organization. These factors have negative effects on perceptions and understanding of an employee and results in a lack of job involvement, job satisfaction, job commitment, and enhancement in job anxiety and quit intention. But there are some other behaviors also which are being addressed in the literature (Aquina \& Thau, 2009; Glomb \& Cortina, 2006; Trevina \& Edmond, 2009), discussed as a 'consequence' of organizational politics.

Taking an autocratic working environment of an organization into the context, it's being found in the literature (Keashly, 1998; Tepper, 2000; Freeman, 2001, 2005; Tepper, 2007; Chan \& McAllister, 2014) that the repeated use of abusive behavior towards the employee working in the organization can affect the psychological well-being of that individual (Keashly 1998, Tepper, 2007) in a way that he opts some safety or defensive behaviors to overcome the issue of being victimized (Freeman, 2001; 2005). These safety behaviors include avoidance, ingratiation \& compliance, aggression, help-seeking (Freeman, 2001; 2005), emotional exhaustion (Tepper, 2000). These behaviors are discussed in the literature as an outcome of the stressed workplace environment. Latterly, these behaviors are discussed as safety behaviors of a paranoid employee reasoning the fact of experiencing excessive abusiveness from the supervisor (Chan \& McAllister, 2014). Fear and anger latterly added as proactive behaviors (Lebel, 2017).

According to the literature (Salkovskis, 1991; Kiazad, Restubog, Zagenczyk, Kiewitz, \& Tang, 2010; Chan \& McAllister, 2014), the research has shown its limitation of different behaviors of employees after experiencing the supervisor's abuse who is having an autocratic personality trait (Kiazad, Restubog, Zagenczyk, Kiewitz, \& Tang, 2010), ultimately results in the adoption of some behaviors to reduce the sense of insecurity which is rarely being discussed in the literature (Salkovskis, 1991), behaviors other than safety behaviors are also opted by the employees working in the organization who perceive job insecurity (Chan, \& McAllister, 2014). These behaviors either when used situationally, even then affect the organization and the other individuals working in the organization also, considered as disruptive political behaviors of an employee in the present study. These behaviors are a core concern in today's research also (Lebel, 2017) which is identified as a literature limitation.

\section{The Objective of the Study}

The research is conducted to check the impact of an autocratic abusive supervisor on the behavioral patterns of the employees working in the organization. As, according to the research, autocratic leaders always require accuracy in the completion of tasks assigned to them, they are doubtful, distrustful, and have negative views regarding the performances of their subordinates (Malik, Saleem, \& Naeem, 2016). The research suggests that there are different behaviors of an employee which appears after experiencing a continuous abuse from his supervisor (Kiazad, Restubog, Zagenczyk, Kiewitz, \& Tang, 2010; Lebel, 2017) who is having an autocratic personality. An obliged environment is created by the supervisor while opting autocratic practices in the organization for meeting the expected targets. Due to this, the supervisor adopts abusiveness towards the employees working in the organization which inhibits a perception of job insecurity in them (Hoel \& Cooper, 
2000; McCarthy et al., 1995; Sheehan, 1996), which will ultimately affect the organizational and individual performance (De Witte, 1999; Sverke et al., 2002).

The research has discussed different behavioral patterns of an employee who works under an autocratic abusive environment but still needs to address more behaviors which an employee opts while perceiving job insecurity (Salkovskis, 1991; Kiazad, Restubog, Zagenczyk, Kiewitz, \& Tang, 2010; Chan \& McAllister, 2014; Lebel, 2017) for securing one's job. For instance, the purpose of conducting present research is: (1) To check the impact of an autocratic leadership on employee's perception of job insecurity while opting abusiveness towards the sub-ordinates to meet the desired outcomes. But in the situation of non-compliance, when an employee is being victimized by a supervisor's abusiveness results in one's perception of job insecurity. This perception of job insecurity encourages disruptive political behaviors in an organization. Reasoning the fact of employee's disruptive political behaviors, the present research conducted is (2) to check the impact of supervisor's abusiveness of an autocratic leader or a boss and employees' perception of job insecurity on one's adoption of disruptive political behaviors in an organization.

\section{Research Questions}

For this instance, the questions which need to be addressed in research are discussed under the main question are as under:

1) How autocratic leadership in terms of abusive supervision and perceived job insecurity will lead to disruptive political behaviors in an organization?

2) How autocratic leadership through abusive supervision is leading to perceived job insecurity of an employee working in the organization?

3) How the disruptive political behaviors of an employee considered to be a consequence of the supervisor's abusiveness and the employee perception of job insecurity?

The proposed framework in the study is providing new insights into the behavioral patterns of an employee who is working under an autocratic abusive supervisor or a boss. Recent studies note that the harsh management and supervisor's manipulative techniques maintain the power in the organization. The presence of this will exaggerate counter-productive behaviors at the workplace (Sackett, Berry, Wiemann, \& Laczo, 2006) which can go against the organizational legitimacy and the deviant workplace behaviors (Kessler, Bandeiii, Spector, Borman, Nelson, \& Penney, 2010). According to the literature (Ferris, Ruth, \& Fandt, 1989; Salkovskis, 1991; Kiazad, Restubog, Zagenczyk, Kiewitz, \& Tang, 2010), the research is showing its contribution of different employee behaviors instead of consequences, after experiencing the supervisor's abuse who inhibits the autocratic personality trait (Kiazad, Restubog, Zagenczyk, Kiewitz, \& Tang, 2010) is rarely being discussed in the literature. Another contribution in the research is that after experiencing the abusive behavior of a boss, different behaviors opted by an employee after perceiving one's job at stake (lack of job security) found as the safety behaviors (Freeman, 2001, 2005; Chan \& McAllister, 2014). Some behaviors other than flattering, help-seeking, ingratiation is discussed as disruptive political behaviors in the study, which is opted by an employee. Some of the behaviors, when studied recently (Lebel, 2017), shows the limitation of these behaviors, which is considered as disruptive political behaviors of employees in the present study, which is also a main contribution in the study. Taking the significance of the research, the study is conducted on telecommunication sector of Pakistan which is having a wide range of workforce who need to fulfill the daily assigned targets given by their executives and in case of not meeting the requirements, the rule of punishments is been chosen reasoning the fact of not dealing with the failures in future. Autocratic leadership is a widely used approach in the subject of leadership. Leadership is the behavioral pattern in which the leader is engaged by dealing with employees or sub-ordinates. The literature acknowledged three leadership styles i.e., Autocratic, Democratic, Laissez-faire (Lewin, Lippit, \& White, 1939). Comparing two of the most important leadership styles, the literature discusses high obedience among workers in democratic organizations, whereas high frustration and anger in the employees while working in the autocratic organization (Schwartz, 1987). Taking both the leadership styles into the context, literature concluded that taking the performance of the employees working in the organization, the democratic leadership is the most effective, but taking productivity of the employees and organization, autocratic leadership is found to be more effective (Lewin et al., 1939; Smith \& Peterson, 1988), but if sustaining good morale and a stable level of work, democratic style of leadership found to be more effective compared to an autocratic one.

The literature discusses the autocratic leaders in a way that they are a classic type of personalities like; "do as I say" type. They retain themselves with the right to make the decision rather than taking any suggestions from their sub-ordinates (Schwartz, 1987). Such a behavioral pattern of a leader declares an absolute authoritative 
control over the subordinates or the followers working in the organization and expecting an undeniable obedience from them (Cheng, Chou, Wu, Huang, \& Farh, 2004, p. 91). If an employee fails in meeting the expected obedience, the supervisor or the leader may react in a harsh way of abusiveness.

\section{Autocratic Leadership and Abusive Supervisory Behavior}

Literature has given a lot of pieces of evidence regarding the supervisor's abusiveness. Most of the work is done by Tepper studying various behaviors of a boss related to his abusiveness. Regarding this, the literature says that supervisor's abusive behavior is a sustained hostile verbal and non-verbal behavior (Tepper, 2000), which an employee face while working in that kind of organization where an organization is having an autocratic structure and the individuals are bound up in a bunch of rules and regulations. This abusive behavior of the supervisor was first studied in 1994 by Keashly, Trott, and MacLean, and latterly by Tepper in 1998. It's also being found in the literature that the employees when work in that kind of environment which is bound under strict rules and policies, are found to work in a pressurized and stressed environment, also reported harsh supervision from the part of their leaders (Hayers, 2000). Such an abusive behavior has harmful effects on the attitudes (like; psychological distress, job dissatisfaction, work-family conflict) and behaviors (job performance, workplace deviance) of an employee who face such behavior and considered as a victim (Tepper, 2000, 2007; Kiazad, Restubog, Zagenczyk, Kiewitz, \& Tang, 2010).

Some consistent reasons for disruption of executives from which some strongly overlap with the dark triad personality, specifically the problems which are associated with social relationships (Van Velsor \& Leslie, 1995). This field of dark triad personality is related with the interpersonal styles like unresponsive, demanding, manipulative, authoritarian, reserved or serious and self-isolating or unsocial, (Lombardo \& McCauley, 1994; Spain, Harms, \& LeBreton, 2014), or egotism, superiority, drama, instability, unnecessary attentiveness, habitual of distrust, aloofness or reserved, mischievousness, unconventionality, submissive confrontation, perfectionism, and enthusiastic to gratify (Dotlitch \& Cairo, 2003; Spain, Harms, \& LeBreton, 2014).

\section{Abusive Behavior \& Job Insecurity}

Taking the perspective of autocratic leadership and abusive supervisory behavior under the approach of Machiavellianism of the dark triad personality, the researchers found evidence that such an abusive behavior of a supervisor which is a sustained hostile verbal or non-verbal behavior towards his followers or subordinates working in an organization (Tepper, 2000), when opted in such an organization where autocratic leadership exists, encourage the level job insecurity in the employees working in an organization. The individual who faces such abusive behavior of his supervisor and is being victimized of such a harsh behavior (Hayers, 2000), affects the attitudes and behavior of the employee working in the organization. Such an abusive behavior has harmful effects on both the attitudes and behaviors e.g., attitudes like; psychological distress, job dissatisfaction, work-family conflict and behaviors like; job performance, workplace deviance of the employee who faces such behavior and considered as a victim (Tepper, 2000, 2007; Kiazad, Restubog, Zagenczyk, Kiewitz, \& Tang, 2010).

In such a situation, a victimized employee found himself to perceive his job insecure while working in the organization. Taking job insecurity into the context, it's being argued in the literature that job insecurity is an employee's helplessness in continuing the anticipated stability in such a threatening situation of the job (Greenhalgh \& Rosenblatt, 1984). Past research has suggested that when an employee is hired in an organization, that employee and the organization enters into a psychological contract in which it is clear on both sides that what one will give and what other will receive (Schein, 1980, p. 22) from both perspectives. Such psychological agreements enhance a sense of mastery of an individual working in the organization that they can control the failing or predicting the proceedings in their worlds. Taking such important factor of sense of control or expectedness of an individual in one's life (cf. Staw, 1977; Sutton \& Kahn, 1986), workplace, personal or job characteristics when threatening his sense of control, encourage some strong responses in return, one of which is the employee's perception of job insecurity (Ashford, Lee, \& Bobko, 1989).

\section{Job Insecurity \& Employee's Political Behaviors}

In Belgium, it's being found that the individual who feels insecure as job insecure union members, feel less supportive behavior from their union, are also found to be less satisfied and show less commitment of unions (De Witte, 2000b; De Witte, Sverke, Van Ruysseveldt, Goslinga, Chirumbolo, Hellgren, \& Näswall, 2008). This research suggested that the member of unions when perceiving their union as less supportive violates their psychological contract with their unions. Because many other employees become members of the union hoping to protect themselves against firing and insecurity (De Witte, 2000b; De Witte, Sverke, Van Ruysseveldt, Goslinga, Chirumbolo, Hellgren, \& Näswall, 2008). 
With this respect, research suggested that perception of job insecurity strengthen the requirement of other members to become a member of a union, who are not the members (De Witte, 2000b). The association of job insecurity is linked with employee's feelings of dissatisfaction, lack of social bonding, and the fear of losing one's job in the current organization. This intentionally turns such behavior into an extreme right-wing elective behavior, like negative attitudes toward the refugees or the migrants (insecure jobholders), which add such members in an insecure union of employees. For this instance, it seems that the perceived job insecurity is playing a vital role to encourage the political climate and to choose the political strategies at the workplace (De Witte et al., 2001; De Witte \& Meuleman, 2007; Stynen \& De Witte, 2011).

Political behaviors at the workplace are frequently used at the workplace and having extensive effects on critical processes like evaluating performance, allocation of resources, and decision-making rights of managers, which influence efficiency and effectiveness of the organization (Kacmar \& Baron, 1999). Taking this perspective into the context, employees when engaging in some organizationally legitimate and authorized political activities which will further be beneficial to the workgroups of organization and organization itself (Fedor, Maslyn, Farmer, \& Bettenhausen, 2008; Chang, Rosen, \& Levy, 2009). For instance, the managers who are having good political capabilities develop large social capital based upon strong bonds which make them to enhance the resources which will be available for their subordinates or the followers (Treadway et al., 2004; Chang, Rosen, \& Levy, 2009).

Employee's political strategies for securing his job leads to show an extra concern to the supervisor by flattering him, seek help from other co-workers of the organization by telling them about such an abusive behavior of his supervisor (Tepper et al., 2008, 2009; Thau et al., 2009; Biron, 2010; Thau \& Mitchell 2010) for gaining sympathies from them or maybe show aggression to the boss in the form of grouping or unions of the organization (Freeman et al., 2001, 2005). These are some of the consequences of experiencing repeated abusive supervisory behavior which can be costly not only for organizations but also for the other targeted individuals of the organization.

\section{Research Gap}

Taking the theoretical background of the research (Ferris, Ruth, \& Fandt, 1989), discusses some of the factors related to job/work environment, personal influence and organizational influence in the model of apparent organizational politics, which were observed but the research limits its study expecting different other behaviors of an employee other than job involvement, job commitment, job anxiety \& stress, job satisfaction and intention to quit (Glomb \& Cortina, 2006; Aquina \& Thau, 2009; Trevina \& Edmond, 2009). This limitation is taken as the first research gap for the present research and contributes to the body of knowledge. Continuing this, latterly, other studies discuss some behaviors of an employee while working in an autocratic environment, which affects the psychological well-being of an employee, after experiencing abusive behavior from their boss, results in the adoption of some different behaviors for securing one's job, which was rarely being discussed in the literature (Salkovskis, 1991; Kiazad, Restubog, Zagenczyk, Kiewitz, \& Tang, 2010). This is considered as the second limitation in literature, the behaviors which an employee opts while working under an autocratic boss are also contributing a body of knowledge in the present research.

Taking the research into the context, the behaviors for securing one's job was discussed (Kiazad, Restubog, Zagenczyk, Kiewitz, \& Tang, 2010), but this research was taken and discussed such behaviors as safety behaviors of an employee who opt these behaviors while being victimized by supervisor's abusiveness for securing his job (Chan \& McAllister, 2014). But still, the research limits its study expecting some other behaviors other than the safety behaviors of an employee who he opts while perceiving job insecurity in an organization, after a supervisor's abusiveness. Recently, the research (Lebel, 2017) discussed anger and fear as proactive behaviors that are used as constructive behavior from the employee side but limit its study in underlying the mechanisms at work which would be sparked as a negative emotion resulting in destructive outcomes (Lebel, 2017). This is another research gap in the literature that makes the present study significant. Taking the literature limitations, the contribution of this study in the literature is the adoption of disruptive political behaviors by an employee to secure one's job which is used against the organization. For this, the research is conducted taking the population of public and private telecommunication sector of Pakistan.

\section{Constructs and Hypothesis}

Taking the construct of autocratic leadership into the context, literature found a high expression of frustration and anger in an autocratic organization (Schwartz, 1987). The followers of autocratic leaders describe this leadership as biding their time, waits for an unavoidable failure which could be generated by this leadership and to remove the leader that follows (Michael, 2010). When autocratic abusive behaviors are used by the 
supervisors, this would create a big issue for an individual working in an organization and make him perceive the fact of insecurity of losing his job. Such autocratic abusive behaviors are perceived as protesting and challenging with other individual's interest who is working in the organization (Vigoda, 2000) which ultimately leads towards disruptive political behaviors. When an individual perceives an insecurity results in opting for the political strategies which would be beneficial only at an employee's side but not for the organization. The use of political strategies to cope up with the perceived job insecurity can also affect the performance of other individuals working in the organization.

The employees who are targeted for political strategies can take steps against the organizational policies which would leave a harmful effect on other employees' jobs, work behaviors, organizational performance, and repute. For securing once the job, the strategies and behaviors opt by the employee working in the organization could be avoidance, compliance, ingratiation, help-seeking, and aggression (Freeman et al., 2001, 2005; Chan \& McAllister, 2014). But the strategies which are disruptive for the organization fall under aggression in the form of grouping, unions, and violence (Freeman et al., 2001, 2005), emotional exhaustion (Tepper, 2000). These strategies could affect the organizational performance which an individual adopts for securing his job. So, the autocratic leadership is making a positive relationship with the politics conducted in the organization.

H1: Autocratic leadership is positively related to employee's disruptive political behaviors in the organization.

Autocratic leaders are classic like; "do as I say" types of personalities. So, they retain for themselves the decision-making rights (Schwartz, 1987). Relating with this, many researchers gave pieces of evidence that the autocratic leaders are undoubtedly strong and directive having four general qualities in them like concerned in making all the important decisions, concerned with task achievement instead of follower's emotions, such leaders maintain a social gap from their followers and motivate followers by threatening them of punishment rather than rewards (Bass \& Bass, 2008; Yukl, 2010). This behavior of a leader declares a complete authority and control over the subordinates or the followers working in the organization while demanding and expecting undeniable obedience from them (Cheng, Chou, Wu, Huang, \& Farh, 2004, p. 91). This expectation of undeniable obedience shows dual effects i.e., affects the supervisor's expectations and the employee perceptions. The supervisor's expectation of meeting the targets or the deadlines makes an employee feel himself at a threatening stage of losing his job.

According to the literature, job insecurity is an individual's perception in understanding his or her existing work environment (Davy et al., 1997; Greenhalgh \& Rosenblatt, 1984). This is an employee's perception that how he or she is perceiving the abusiveness of the supervisor, either as an organizational structural policy or as a behavioral aspect. Taking this perspective, in actual job insecurity is different from losing a job, if considering two different employees working in the same organization are exposed for same organizational objectives, they will perceive the risk of losing a job differently from each other (Loi, Lam, \& Chan, 2012). Taking this view, the present study discusses that the autocratic leader when adopts harsh/abusive behavior towards the subordinates working in the organization, that individual who is being victimized perceives his job at stake. The employee's perception of job insecurity is linking with the abusive behavior which the supervisor or the boss adopts in the situations of non-compliance. The behavioral aspect of an autocratic leader i.e., abusiveness towards the subordinates usually incur the threats in him like; punishment instead of rewards (Bass \& Bass, 2008; Yukl, 2010) and the abusive behavior (Tepper, 2000), leads to the employee perception of job insecurity.

H2: Autocratic leadership is positively related to the employee's perception of job insecurity.

H3: Autocratic leader when opt abusiveness is positively related to an employee's perception of job insecurity.

These strategies are adopted only when the employee perceives his job insecure in a way that he may lose his job due to such an abusive behavior of an autocratic leader. This abusive behavior of an autocratic supervisor is perceived insecure due to strict following up the rules and policies, as per defined. Different empirical studies demonstrated that employees who are being victimized of supervisor's behavior of abusiveness, tends to react against the organization and the other individuals at work, for the abuse they experience (Biron, 2010; Tepper et al., 2009, 2008; Thau et al., 2009; Thau \& Mitchell, 2010, Chan \& McAllister, 2014). Thus, when an autocratic leader opts for abusive behavior in the organization to meet the expected targets, it enables an employee to perceive his job insecurity, which can continue other types of deviant behaviors, which may be costly not only for the organizations but also for the innocent bystanders. So, taking the literature into the context, the employee's perception of job insecurity (due to an autocratic leadership which exists in the organization) is showing a positive relationship with disruptive political behavior of an employee currently working.

H4: Employee's perception of job insecurity is positively related to disruptive political behaviors. 
Taking the generated hypothesis from the literature review into the context, the proposed framework falls under the model of perceived organizational politics. According to the model of perceived organizational politics (Ferris, Russ, \& Fandt, 1989), the variables are showing a positive relationship resulting in disruptive political behaviors. According to the model of perceived organizational politics (Ferris, Russ, \& Fandt, 1989), the work environment influences the behaviors of the individuals working in the organization especially the interaction of supervisors and co-workers. Secondly taking the personal influence into the context the directive/autocratic style of the supervisor highlights the concept of Machiavellian. The autocratic abusive supervisors focus more on power and competition, they not only wish to achieve, and they wish to do so at the expense of others (Jones, Daniel, Paulhus, \& Delroy, 2009).

According to the research, organizations merge three factors of maintaining power, using harsh management tactics and manipulative behaviors. This when present in an organization is positively related to counterproductive workplace behaviors (the behavior of an employee which goes against the legitimate interests of an organization) (Sackett, Berry, Wiemann, \& Laczo, 2006) and deviant workplace behaviors (Kessler, Bandeiii, Spector, Borman, Nelson, \& Penney, 2010). These authoritative and abusive supervisory behavior makes an employee perceive his job at stake (as per discussed above in the model of POP) (Ferris, Ruth, \& Fandt, 1989 ) and the employee's perception of job insecurity is making a positive relationship with disruptive political behaviors at workplace.

\section{Research Model}

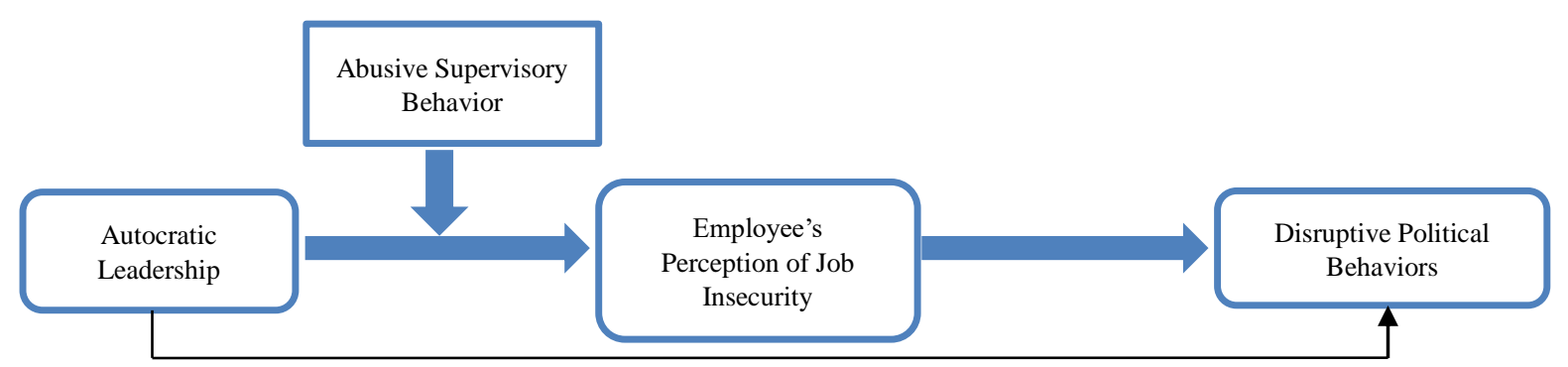

Proposed Framework on the model Perceived Organizational Politics (POP) (Ferris, Russ, \& Fandt, 1989).

\section{Research Methodology}

The methodology is an organized and theoretical analysis of the methods which are applied to the field of study. The comprised theoretical analysis of the body of methods and principles of the research conducted is associated with a branch of knowledge. Taking this factual knowledge, it includes different concepts such as; research paradigm, theoretical model, different stages, and research techniques like qualitative or quantitative (Irny \& Rose, 2005). This chapter presents the whole data from which the study has gone through. The use of analysis, methods, techniques, and paradigm is discussed with respondents of data. The data collected from the research instruments available. The sample chosen from the population is the core data of analysis on which descriptive and inferential analysis conducted.

The process through which the researcher researched exploring the knowledge while applying research methodology. The research methodology is explained as the strategic approach of exploring the data which simple explanations and interpretations by collecting empirical data (Wainwright, 1997). Therefore, an important step of research methodology is to select a suitable paradigm. The selection of paradigm starts by determining the epistemology and ontology of the research (Denzin \& Lincoln, 2008). Political researchers work on the foundations of ontological and epistemological positions. These approaches are not spelled out explicitly or implicitly but show them in the methodological approaches. According to the research conducted, the quantitative method follows the epistemological approach. The approach 'epistemology' is the theory of knowledge that reflects the view of knowing about the world in a way that what we can know and how we can know (Marsh \& Furlong, 2002).

With this view, the epistemology is either objective or subjective. Objectivity states that the knowledge is governed by the law of nature whereas, subjectivity states that the knowledge is, it is created by the perceptions of a researcher. The present study conducted follows the objective epistemology because knowledge has taken already exist and there are no perceptual interpretations. Ontology explains that how one perceives a reality (Wahyuni, 2012) or how one sees the world. Ontology is further divided into two categories i.e., realistic and 
relativistic ontology. Realistic ontology explains the existence of reality (Pamela \& Richard, 1994) whereas, relativistic ontology explains the perceptual interpretations of a knowledge that the nature is socially constructed and is free from nature laws (Lincol, Lynham, \& Guba, 2011). The present study shows the realistic ontology due to the cause and effect relationship between the constructs AL, AS, PJI \& DPB.

Paradigms are studied at the beginning of the research design. It is a loose collection of logical assumptions, concepts, and propositions which turn the person's thinking and research (Bogdan \& Biklen, 1998). It can also be called a philosophical intention or motivation for undertaking a study (Cohen \& Manion, 1994). The research is quantitative, so it falls under the 'positivist paradigm'. 'Positivism is referred' as scientific method which is purely based on rationalist and empirical philosophy (Mertens, 2005) and shows the reflection of deterministic philosophy in which the causes regulate the effects and outcomes (Creswell, 2003). Positivists aim to describe the experience or we can say that they test the theory through observation and measurement to predict and control the forces which are present around us (O'Leary, 2004). Research design is a detailed plan which focuses on the collection of data, procedures of sampling, and the assessment measures required in the research. The main idea, purpose, and design of the research classifies the research into the explanatory, correlational, experimental, semi-experimental, review, or meta-analysis (Bhatacherjee, 2012). These types of studies further divided into different categories like cross-sectional, longitudinal, survey research or cohort study (Bryman \& Bell, 2007). The present study conducted on a cross-sectional research design focusing on survey questionnaires which will be collected on a single time.

\subsection{Assessment Measures}

Survey questionnaires were used to collect the data which was based on 47 items. The details are mentioned in Table 1.

Table 1. The population selected is the telecommunication sector of Pakistan

\begin{tabular}{lll}
\hline Assessment Measures & Sources & No. of Items \\
\hline Autocratic Leadership Scale (ALS) & Cheng et al. (2000) & 9 -items \\
Abusive Supervision Scale (ASS) & Tepper (2000) & 11-items \\
Job Insecurity Scale & Susan J. Ashford, Cyntffla lee, Philip Bobko (1989); & 12-items \\
& Johnson, Messe, and Crano's (1984). & 15 -items \\
\hline
\end{tabular}

The population selected is the telecommunication sector of Pakistan. The selected sampling frame was the middle and front-line managers and their employees who were working in the telecommunication sector. From which, the data was collected from the telecommunication sector of Lahore. The sample includes only the permanent employees who were working presently and were asked to fill the questionnaires. For this purpose, the employees who were having a minimum of 6 months of present job experience with a minimum qualification of intermediate were chosen for the collection of data. The minimum age allowed to fill the questionnaires was 20 years and the maximum was 60 years of age.

The unit of analysis was the individuals working in the organizations on the managerial posts of middle and front-line and the employees or the subordinates, from the public and private telecommunication sector of Lahore.

The present study determines the sample size from the no. of items (Haier et al., 2009). It demonstrates that there must be $5-10$ observations for every item. So according to this, the sample size calculated is $(5 \times 47)$ which is equal to 248 respondents.

There are two sources of collecting data i.e., primary source and secondary source. The primary source for collecting data is the self-generated data which is being collected personally through survey questionnaires. Whereas, the data collected from the secondary sources are from research papers, books, data records, etc. The source used in the study for the collection of data is the primary source.

\subsection{Autocratic Leadership (AL)}

Autocratic leaders are classic are like; "do as I say" type of personalities. They retain themselves with the right to make the decision rather than taking any suggestions from their sub-ordinates (Schwartz, 1987). Such a behavioral pattern of a leader declares an absolute authoritative control over the subordinates or the followers working in the organization and expecting undeniable obedience from them (Cheng, Chou, Wu, Huang, \& Farh, 2004, p. 91). 


\subsection{Abusive Supervision (AS)}

The supervisor's abusive behavior is a sustained hostile verbal and non-verbal behavior (Tepper, 2000). The employees when work in a pressurized and stressed environment, reported harsh supervision from the part of their leaders (Hayers, 2000). Such an abusive behavior has harmful effects on both the attitudes \& behaviors of an employee who face such behavior and considered as a victim (Tepper, 2000, 2007; Kiazad, Restubog, Zagenczyk, Kiewitz, \& Tang, 2010).

\subsection{Perceived Job Insecurity (PJI)}

An individual's job insecurity emerged an unthreatened situation of employment (Rosenblatt \& Ruvio, 1996; Vetting, 2010). With this regard, the total number of employees perceive their job considerably as threatened (De Witte, 2005). It's been demonstrated that an individual's perception of job insecurity is linked with various negative outcomes of employees in the form of well-being (Sverke, Hellgren, \& Näswall, 2002; Cheng \& Chan, 2008), turnover ratio (Probst, 2008; Staufenbiel \& König, 2010) and decrease in employee's OCBs (organizational citizenship behaviors) (Reisel et al., 2010).

\section{Disruptive Political Behaviors}

When an employee is emotionally exhausted by being victimized of the supervisor's behavior of abusiveness (Tepper, 2000), the research shows that such employees to react negatively against the organization and also other individuals working in the organization for the abuse they experience (Biron, 2010; Tepper et al., 2009, 2008; Thau et al., 2009; Thau \& Mitchell, 2010). These deviant acts opted by the employee because of abusive behavior of a supervisor which created a perception of job insecurity in an employee resulting in the adoption of disruptive political behaviors like; showing aggressive behavior to a boss in the form of grouping, unions, and violence (Freeman et al., 2001, 2005), emotional exhaustion (Tepper, 2000).

\section{Statistical Treatment of Data}

Following the data collection method, the data collected is analyzed through SPSS version 21 and discussed by portraying the research questions of the study. The statistical data analysis applied was:

1) The descriptive analysis which includes mean, standard deviation or SD to check the consistency of the constructs.

2) Co-relation of the variables AL, AS, EPJI \& DPB.

3) Reliability and validity among the variables.

4) Inferential statistics which includes mediation and moderation through regression analysis. Mediation analysis applied to assess the mediating role of employee's perception of job insecurity and moderation analysis to access the moderating role of abusive supervisory behavior.

5) Moderation test analysis of autocratic leadership and employee's perception of job insecurity with the moderating effect of abusive supervisory behavior, done through regression (Rebecca, 2012).

6) Sobel test (Sobel, 1982) and Preacher \& Hayes test (Preacher \& Hayes, 2008) applied for mediation i.e., employee's perception of job insecurity in the present study.

As the data is collected from the telecommunication sector of Lahore, Pakistan. For analysis, in the beginning, this chapter represents the demographic information of the respondents of the questionnaires used for this study. Concerning this, after conducting EFA, mediation \& moderation is been tested through regression. This chapter also includes the results of data conducted through the Sobel test and Preacher \& Hayes test. The prior test of CFA (confirmatory factor analysis) runs on the tools which are to be used for data collection. This is commonly used in social research (Kline, 2010). CFA is a statistical procedure for multi-variation which is used to check that how better the variables are measured according to the understanding of the researcher regarding the nature of those particular constructs. In short, the main objective of CFA is to test that either the data fits into the hypothetical model of measurement or not (Preedy \& Watson, 2009).

While conducting CFA, the items whose values are $\geq 0.7$ are taken under notice for data collection items. So, after doing CFA, the items reduced to 47 from 79 of the previous tools. According to Hair et al. (2009), the data is collected on a 5 -item Likert scale i.e., from 1 (Strongly Disagree) to 5 (Strongly Agree). So according to this, the number of respondents is $n=248$.

\section{Demographic Analysis}

The demographics are taken into notice. The characteristics of the respondents $(n=248)$ based on the gender (male \& female), age (minimum 20 years and maximum 60 years) so that the data collected according to their 
personal job experiences, education (minimum intermediate but not less than that and maximum no limit) so that respondent can understand the language and value of a questionnaire, hierarchical level (middle \& front-line managers and their subordinates) so that we would be able to check the flow of orders and the level of perception of employees and the outcomes according to the set boundaries of a boss, and lastly the experiences are also taken into the notice of the employees (6 months or above), front-line \& middle managers (5-15 years, 15-25 years and above) so that they must know that how to work in the organization and what experiences they have while working in the organization. The demographics are shown in Table 2 below:

Table 2. Cross-sectional technique with a sampling strategy of convenient

\begin{tabular}{|c|c|}
\hline Characteristics \& \% Age & Frequency \\
\hline \multicolumn{2}{|l|}{ Gender } \\
\hline Male $73.1 \%$ & 182 \\
\hline Female $26.80 \%$ & 66 \\
\hline \multicolumn{2}{|l|}{ Age } \\
\hline$<25$ years $=10 \%$ & 24 \\
\hline $25-40$ years $=71 \%$ & 176 \\
\hline $40-60$ years $=20 \%$ & 49 \\
\hline \multicolumn{2}{|l|}{ Education } \\
\hline Intermediate $=5.4 \%$ & 13 \\
\hline Graduation $=37.87 \%$ & 93 \\
\hline Masters $=46.80 \%$ & 118 \\
\hline Above Masters $=9.78 \%$ & 24 \\
\hline \multicolumn{2}{|l|}{ Hierarchical Level } \\
\hline Middle Level Managers $=15 \%$ & 37 \\
\hline Front-line Managers $=20.42 \%$ & 51 \\
\hline Subordinates $=64.25 \%$ & 160 \\
\hline \multicolumn{2}{|l|}{ Experience } \\
\hline 6 months $<5$ years $=24.25 \%$ & 60 \\
\hline $5-15$ years $=39.14 \%$ & 97 \\
\hline $15-25$ years $=25.53 \%$ & 63 \\
\hline$>25$ years $=11.06 \%$ & 28 \\
\hline
\end{tabular}

As the study based on a cross-sectional technique with a sampling strategy of convenient based sampling so the data collected is based on convenience. So according to the survey, the questionnaires are filled by males and females working in the organization that is $n=248$ from which the ratio of male working is greater than the females working in the organization (male=73.1, female 26.80). According to the survey, the collected data shows the age limit defined in the strategy as not less than 20 and not greater than 60 years. With respect to this, in the slot of $<25$ years $(n=24), 25-45$ years $(n=169)$ and $45-60$ years $(n=48)$ respondents were there.

As defined above in the sampling of the study regarding the education of the respondents. The data must be collected from those respondents who are capable to understand and read the questionnaire. So the respondents of the study must have minimum qualifications for 12 years. So according to the collected data, the respondents having 12 years of education $(n=13), 14-16$ years of education $(n=89), 16-18$ years of education $(n=110)$, and above 18 years of education $(n=23)$. With this respect, as defined above that the respondents of data must be the front line or middle line managers and their subordinates working in the organization. So the questionnaires are distributed in the organizations and the respondents as middle-line managers $(n=36)$, front-line managers $(n=48)$, and the employees working under them $(n=151)$. Regarding autocratic leadership, respondents give their feedback which was completely based on their perceptions that how they take their supervisor's behavior and what are their opinions about it. Concerning their experiences while working in the organization matters a lot. According to the present study, the respondents must have the minimum experience of 6 months and for maximum no limit. The data shows that the employees having experience of 6 months to 5 years $(\mathrm{n}=57)$ is $24.25 \%, 5-15$ years $(n=92)$ is $39.14 \%, 15-25$ years $(n=60) 25.53 \%$ and experiences greater than 25 years $(n=26)$ $11.06 \%$ of the respondents. This shows that the data collected from the respondents, having enough experience to understand the organizational culture and in support to this, their opinions taken are discussed in the present research. 


\section{Validity and Reliability of an Instrument}

While conducting empirical research, it is very important to check the reliability of an instrument we use for the collection of data. To check the reliability and validity of an instrument, the value of Cronbach's Alpha must be greater than equal to 0.5. It's been defined in the previous study that Cronbach's Alpha is used to check the internal consistency of the tools used in the study (Cortina, 1993). According to the study of Hair et al. (2009), the minimum acceptable value of 'alpha $\alpha$ ' 0.6 and further it's been argued that the $\alpha$ must be greater than 0.7 which also needs to be positive (Cooper \& Schindler, 2008). Table 3 explains the instrument reliability.

The scales used in the present study for Autocratic Leadership consists of 9 items is having the reliability value $\alpha=0.840$. The scale used for Abusive Supervisory Behavior consists of 11 items is having the reliability of $\alpha=0.913$. The scale used for Employee's Perception of Job Insecurity consists of a 12 -items scale $\alpha=0.853$. The scale used for Disruptive Political Behavior consists of a 15 -items scale $\alpha=0.898$. This shows that the tools used for the present study are highly reliable.

Table 3. Scales used in the present study for Autocratic Leadership)

\begin{tabular}{lcc}
\hline Scale Name & No. Of Items & Cronbach's Alpha value ( $\boldsymbol{\alpha})$ \\
\hline Autocratic Leadership & 09 & 0.840 \\
Abusive Supervisory Behavior & 11 & 0.913 \\
Employee Perception of Job Insecurity & 12 & 0.853 \\
Disruptive Political Behavior & 15 & 0.898 \\
\hline
\end{tabular}

In this section, mean, median, standard deviations, and correlations are discussed among the main study variables which are calculated and presented in table 3. In the table shown below, Autocratic Leadership is represented as AL, Abusive Supervisory Behavior is represented as ASB, Employee perception of Job Insecurity is represented as EPJI, and Disruptive Political Behavior is represented as DPB.

Table 4. Descriptive analysis (mean, median, standard deviations and correlations)

\begin{tabular}{|c|c|c|c|c|c|c|c|c|c|c|}
\hline \multirow{2}{*}{ Variables } & \multirow{2}{*}{$\mathbf{N}$} & \multirow{2}{*}{ Min. } & \multirow{2}{*}{ Max. } & \multicolumn{2}{|c|}{ Mean } & \multirow{2}{*}{$\frac{\text { Std. Deviation }}{\text { Statistic }}$} & \multicolumn{2}{|c|}{ Skewness } & \multicolumn{2}{|c|}{ Kurtosis } \\
\hline & & & & Statistic & Std. Error & & Statistic & Std. Error & Statistic & Std. Error \\
\hline 1. $\mathrm{AL}$ & 248 & 1.22 & 5.00 & 3.1541 & .04929 & .77629 & .160 & .155 & -.061 & .308 \\
\hline 2. ASB & 248 & 1.00 & 4.64 & 2.5557 & .05601 & .88206 & .547 & .155 & -.533 & .308 \\
\hline 3. EPJI & 248 & 1.17 & 4.67 & 3.1220 & .04400 & .69288 & -.126 & .155 & -.474 & .308 \\
\hline 4. DPB & 248 & 1.27 & 4.73 & 3.2027 & .04466 & .70336 & -.125 & .155 & -.134 & .308 \\
\hline
\end{tabular}

In the table shown above, the minimum and the maximum value represents the lower and the higher value in the observations. The table shows the skewness in the values. If the value is positive than the data is positively skewed but if the value is negative than the data is negatively skewed. Skewness value is explained by Bulmer (1979), which is between -1 to +1 . In the table shown above, the values lie in the field. The studies show that the kurtosis value lies between 0 to $+3,-3$, he values lie in the field.

According to Field (2009), co-relation analysis is used to check the covariance among the variables used in the study. It explains the relationship between an independent and dependent variable. So here the Pearson Correlation Analysis is been conducted to check the co-variance among autocratic leadership, abusive supervisory behavior, employee perception of job insecurity, and disruptive political behavior. The required respondents are $n=248$ ( $n$ is representing no. of respondents. Correlation is represented with ' $r$ ' and the values mentioned in the table below are highly correlated with each other. Whereas, according to the past studies, the significance value is $\mathrm{p}<0.01$ and the table shows that the values are highly significant.

According to analysis, ASB is positively correlated and highly significant with AL ( $r=0.684, p<0.01$ ), EPJI is positively correlated and highly significant with AL $(r=0.49, \mathrm{p}<0.01)$ and ASB $(r=0.44, p<0.01)$, DPB is also positively correlated and highly significant with AL $(r=0.56, p<0.01)$, ASB $(r=0.44, p<0.01)$ and EPJI $(r=0.54$, $\mathrm{p}<0.01$ ). 
Table 5. Correlation analysis (this is an example of table 4 mean, median, standard deviations and correlations)

\begin{tabular}{|c|c|c|c|c|c|}
\hline & & $\mathbf{A L}$ & ASB & EPJI & DPB \\
\hline \multirow{4}{*}{$\mathbf{A L}$} & Pearson Correlation & 1 & & & \\
\hline & Sig. (2-tailed) & & & & \\
\hline & $\mathrm{N}$ & 248 & & & \\
\hline & Pearson Correlation & $.684^{* *}$ & 1 & & \\
\hline \multirow[t]{3}{*}{ ASB } & Sig. (2-tailed) & .000 & & & \\
\hline & $\mathrm{N}$ & 248 & 248 & & \\
\hline & Pearson Correlation & $.549^{* *}$ & $.448^{* *}$ & 1 & \\
\hline \multirow[t]{3}{*}{ EPJI } & Sig. (2-tailed) & .000 & .000 & & \\
\hline & $\mathrm{N}$ & 248 & 248 & 248 & \\
\hline & Pearson Correlation & $.567^{* *}$ & $.443^{* *}$ & $.546^{* *}$ & 1 \\
\hline \multirow[t]{2}{*}{ DPB } & Sig. (2-tailed) & .000 & .000 & .000 & \\
\hline & $\mathrm{N}$ & 248 & 248 & 248 & 248 \\
\hline
\end{tabular}

According to Field (2009), regression analysis is discussed as a method or a technique that is normally used to predict an outcome variable by one or more than one variable. In the regression analysis, the independent variable is known as a 'predictor' and the dependent variable is known as 'outcome variable'. In the present study, mediation and moderation is been tested through regression analysis. In the present study, the regression analysis is run on the data collected from the respondents. As the analysis discussed above shows the correlation among the variables. Taking this into the context, when the regression run on the variable relation, the values of $\mathrm{R}^{2}$, tolerance level (t), variation in frequency (VIF), coefficient beta value and significance among the variables are taken into notice to check the acceptance of a hypothesis. $\mathrm{R}$ square shows that there is a variation in the variables. Conducting research, the variation is a must and the value must not be equal to zero. Beta value tells that the variation is there independent and independent variables i.e., how much the dependent variable is expected to increase if when the independent variable increases by

\section{$15.1 A L \& D P B$}

Considering Autocratic Leadership (AL) as an independent variable and taking Disruptive Political Behavior (DPB) as a dependent variable. The value of $\mathrm{R}^{2}=0.540$ which shows that there is a variation in the model, the estimated standard error is 0.463 and the model is considered as significant with the value $<0.05$. This is shown in the table of the model summary of the variable in Table 6 below:

Table 6. Model summary AL \& DPB

\begin{tabular}{lccccccc}
\hline & & & & \multicolumn{3}{c}{ Change Statistics } \\
\cline { 3 - 7 } 1 & Rodel & R Square & Adjusted R Square & Std. Error & R Square Change & F Change & Sig. F Change \\
\hline $.735^{\mathrm{a}}$ & .540 & .532 & .46374 & .540 & 69.238 & .000 \\
\hline
\end{tabular}

a. Predictors: (Constant), AL

b. Dependent Variable: DPB

Taking this into the context, the tolerance value and the variance inflation is discussed in the table i.e., tolerance value is less than 10 , and the variance inflation value is greater than 0.1 . So it shows that it supports the arguments of multi-collinearity. According to the coefficient, the beta value is 0.735 which means that if an increase of 1 point in independent variable AL would expect to increase the dependent variable DPB by 0.735 .

The tab there is a correlation among the variables and also showing the high significance among the variables that the $\mathrm{p}<0.01$.

Table 7. Coefficient analysis result

\begin{tabular}{|c|c|c|c|c|c|c|c|c|}
\hline \multirow{2}{*}{ Model } & \multicolumn{3}{|c|}{ Standardized Coefficients } & \multicolumn{3}{|l|}{ Correlations } & \multicolumn{2}{|c|}{ Collinearity Statistics } \\
\hline & Beta & $\mathbf{t}$ & Sig. & Zero-order & Partial & Part & Tolerance & VIF \\
\hline (Constant) & & 5.138 & .000 & & & & & \\
\hline AL & .735 & 8.321 & .000 & .735 & .735 & .735 & 1.000 & 1.000 \\
\hline
\end{tabular}

a. Dependent Variable: DPB

According to the results shown in the tables above, the variable is showing the high significance so we can say 
that an Autocratic leadership is affecting the employees to opt disruptive political behaviors in the organization.

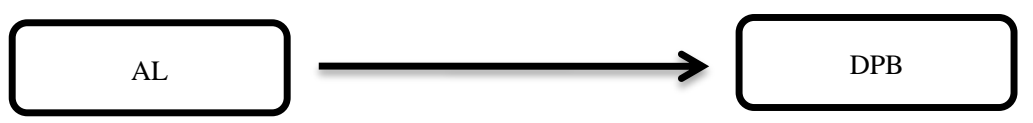

\section{$15.2 A L \& E P J I$}

Considering Autocratic Leadership (AL) as an independent variable and taking Employee's Perception of Job Insecurity (EPJI) as a dependent variable. The value of $\mathrm{R}^{2}=0.302$ which shows that there is a variation in the model, the estimated standard error is 0.580 and the model is considered as significant with the value $<0.05$.

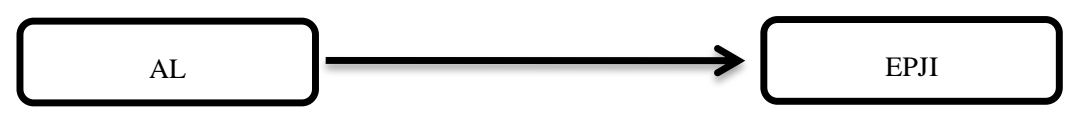

Table 8. Model summary AL \& EPJI

\begin{tabular}{lcccccc}
\hline \multirow{2}{*}{ R } & \multirow{2}{*}{ R Square } & Adjusted R Square & \multirow{2}{*}{$\begin{array}{c}\text { Std. The error of the } \\
\text { Estimate }\end{array}$} & \multicolumn{3}{c}{ Change Statistics } \\
\cline { 5 - 7 } & .302 & .299 & .58014 & R Square Change & F Change & Sig. F Change \\
\hline $.549^{\mathrm{a}}$ & & & & .302 & 106.333 & .000 \\
\hline
\end{tabular}

a. Predictors: (Constant), AL

b. Dependent Variable: EPJI

Taking this into the context, the tolerance value and the variance inflation is discussed in table 5.8.1 (b) i.e., tolerance value is less than 10 , and the variance inflation value is greater than 0.1 . So it shows that it supports the arguments of multicollinearity. According to the coefficient, beta value is 0.156 which explains that the increase of 1 point in independent variable AL would increase the dependent variable EPJI by 0.156. The table 5.8.1 (b) shows that there is a correlation among the variables and also showing the high significance among the variables that the $\mathrm{p}<0.01$.

Table 9. Coefficient analysis result

\begin{tabular}{lcccccccc}
\hline \multirow{2}{*}{ Model } & $\begin{array}{c}\text { Standardized Coefficients } \\
\text { Beta }\end{array}$ & T & Sig. & Zero-order & Partial & Part & \multicolumn{2}{c}{ Collinearity Statistics } \\
& & & & Tolerance & VIF \\
\hline Constant & & 10.201 & .000 & & & & & \\
AL & .549 & 10.312 & .000 & .549 & .549 & .549 & 1.000 & 1.000 \\
\hline
\end{tabular}

a. Dependent Variable: EPJI

According to the results shown in the tables above, the variable is showing the high significance in the direct relation of AL to EPJI. This shows that autocratic leadership is affecting the attitudes of employees that they perceive their job insecurity while working in the organization.

\subsection{AL \& EPJI with Moderating Effect of ASB}

Considering Autocratic Leadership (AL) as an independent variable with the moderating effect of Abusive Supervisory Behavior (ASB) and Employee's Perception of Job Insecurity (EPJI) as a dependent variable. According to Rebecca M. Warner (2012), the moderation analysis is conducted through regression which shows the value of $\mathrm{R}^{2}=0.105$ shows that there is a variation in the model, the estimated standard error is 0.656 and the model is considered as significant with the value $\leq 0.05$.

Table 10. Model summary of moderation analysis

\begin{tabular}{lcccccc}
\hline $\mathbf{R}$ & \multirow{2}{*}{ R Square } & \multirow{2}{*}{ Adjusted R Square } & \multirow{2}{*}{ Std. Error } & \multicolumn{3}{c}{ Change Statistics } \\
\cline { 5 - 7 } & & & & R Square Change & F Change & Sig. F Change \\
\hline $.323^{\text {a }}$ & .105 & .101 & .65698 & .105 & 28.731 & .000
\end{tabular}

a. Predictors: (Constant), AL by EPJI

Taking this into the context, the tolerance value and the variance of inflation is discussed in table 11 . For AL tolerance value is less than 10 and equals to 1.000 and the variance inflation value is greater than 0.1 which is equal to 1.000 . Similarly, the tolerance value for the moderation is 1.000 and also showing the same results for 
variance inflation as 1.000. According to the coefficient beta value of the moderation of AL by ASB is 0.323 which means that if an increase of 1 point would expect to increase the dependent variable EPJI by 0.323 . Table 5 shows that there is a correlation among the variables and also showing the high significance among the variables that the moderation ASB is completely affecting the relationship of AL \& EPJI that the $p \leq 0.01$. It means that the moderation of Abusive Supervisory Behavior is completely significant which proves the $\mathrm{H} 3$ of the present research. This all values are shown in Table 11 below.

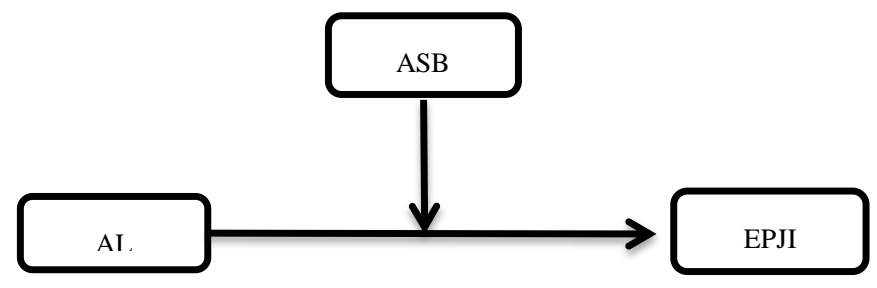

Table 11. Moderation analysis (this is an example of the table this all (Dependent Variable), AL by EPJI)

\begin{tabular}{lllllllll}
\hline Model & $\begin{array}{l}\text { Standardized Coefficients } \\
\text { Beta }\end{array}$ & T & Sig. & $\begin{array}{l}\text { Correlations } \\
\text { Zero-order }\end{array}$ & Partial & Part & $\begin{array}{l}\text { Collinearity Statistics } \\
\text { Tolerance }\end{array}$ & VIF \\
\hline (Constant) & & 61.937 & .000 & & & & & \\
AL by ASB & .323 & 5.360 & .000 & .323 & .323 & .323 & 1.000 & 1.000 \\
\hline
\end{tabular}

a. Dependent Variable: EPJI

According to the results shown in the tables above, moderation is showing a high significance among the variable relation. Concerning this, moderation is supporting the proposed model that when an autocratic leader opts an abusive behavior than the employee perceives his job insecure.

\subsection{AL \& DPB with Mediating Effect of EPJI}

Considering Autocratic Leadership (AL) as an independent variable to check the mediation effect of Employee's Perception of Job Insecurity (EPJI) with the dependent variable of Disruptive Political Behavior (DPB). The value of $\mathrm{R}^{2}=0.564$ which shows that there is a variation in the model, the estimated standard error is 0.455 and the model is considered as significant with the value $<0.05$.

Table 12. Model summary AL, EPJI \& DPB

\begin{tabular}{ccccccc}
\hline $\mathbf{R}$ & R Square & Adjusted R Square & Std. Error of the Estimate & \multicolumn{3}{c}{ Change Statistics } \\
& & & & R Square Change & F Change & Sig. F Change \\
\hline $.751^{\mathrm{a}}$ & .564 & .549 & .45540 & .540 & 69.238 & .000 \\
\hline
\end{tabular}

a. Predictors: (Constant), EPJI, AL

Taking this into the context, the tolerance value and the variance of inflation is discussed in table 13 . For AL tolerance value is less than 10 and equals 1.000 and the variance inflation value is greater than 0.1 which is equal to 1.000. Similarly, the tolerance value for EPJI is 0.987 , and the variance inflation value is 1.013 . According to the coefficient beta value of AL is 0.717 and for EPJI is 0.156 which means that if an increase of 1 point in independent variable AL \& EPJI would expect to increase the dependent variable DPB by $0.717 \& 0.156$. Table 13 shows that there is a correlation among the variables and also showing the $90 \%$ significance among the variables that the $\mathrm{p}=0.80$ which is less than the significance value $\mathrm{p}=0.10$. It means that the mediation EPJI is partially significant.

Table 13. Coefficient analysis results

\begin{tabular}{|c|c|c|c|c|c|c|c|c|}
\hline \multirow{2}{*}{ Model } & \multicolumn{2}{|l|}{ Standardized Coefficients } & \multirow{2}{*}{ Sig. } & \multicolumn{2}{|c|}{ Correlations } & \multicolumn{3}{|c|}{ Collinearity Statistics } \\
\hline & Beta & t & & Zero-order & Partial & Part & Tolerance & VIP \\
\hline (Constant) & & .763 & .449 & & & & & \\
\hline $\mathrm{AL}$ & .717 & 8.213 & .000 & .735 & .735 & .735 & 1.000 & 1.000 \\
\hline EPJI & .156 & 1.783 & .080 & .228 & & & 0.987 & 1.013 \\
\hline
\end{tabular}

a. Dependent Variable: DPB

b. Predictor in the model: AL

Note. This is an example of table this all (Dependent Variable: DPB Predictor in the model: AL) coefficient analysis results. 
According to the results shown in the tables above, the mediation is showing more than $90 \%$ significance among dependent and independent variable i.e., AL \& DPB. So, this shows that when having an autocratic culture in the organization, an employee's perception of job insecurity is a partial reason for employees to opt for disruptive political behavior.

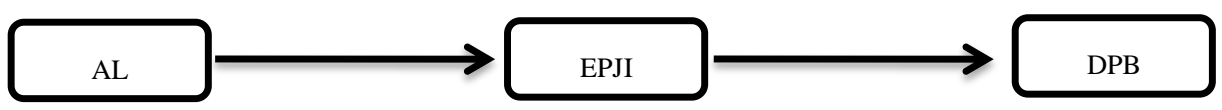

\begin{tabular}{|c|c|c|c|c|}
\hline Input: & & Test statistic: & Std. Error: & $p$-value: \\
\hline a 0.49 & Sobel test: & 1.74274284 & 0.07310316 & 0.08137854 \\
\hline$b 0.26$ & Aroian test: & 1.73468114 & 0.07344289 & 0.0827973 \\
\hline$s_{a} 0.048$ & Goodman test: & 1.75091799 & 0.07276183 & 0.07996004 \\
\hline$s_{\mathrm{b}} 0.147$ & Reset all & & Calculate & \\
\hline
\end{tabular}

Figure 1. Sobel test

The mediation of the model can be tested for significance with an estimated standard error (Sobel, 1982).

The purpose of doing a Sobel test is that either the mediator is influencing the relation of the independent and dependent variable or not. In the present study, the Sobel test is conducted to test the direction of autocratic leadership with an indirect effect of employee's perception of job insecurity on disruptive political behavior.

In the figure shown above, the statistics, standard error, and the p-value are shown. The values shown in the figure are almost the same and match the result of the regression analysis run for mediation of the present study. Test statistics are showing the standardized beta results of independent variable autocratic leadership with dependent variable disruptive political behavior with the mediating effect of employee perception of job insecurity. Similarly, with the same IV, DV \& MV, the standard error and the significance value is showing the same results and showing that the partial mediation exists in the present study. The mediator is not completely significant but showing $90 \%$ significance in the model.

\section{Direct and Indirect Effect}

As per the theory of mediation, from different calculations direct and indirect effects are been tested here (See fig.5.9 (b)),

$$
\begin{aligned}
& \text { Total Effect }=\text { Direct Effect }+ \text { Indirect Effect } \\
& \mathbf{C}=\dot{\mathbf{C}}+\text { (a) (b) }
\end{aligned}
$$

Putting the values in the equation:

$\mathrm{C}=0.59+(0.49)(0.26)$

$\mathrm{C}=0.717$

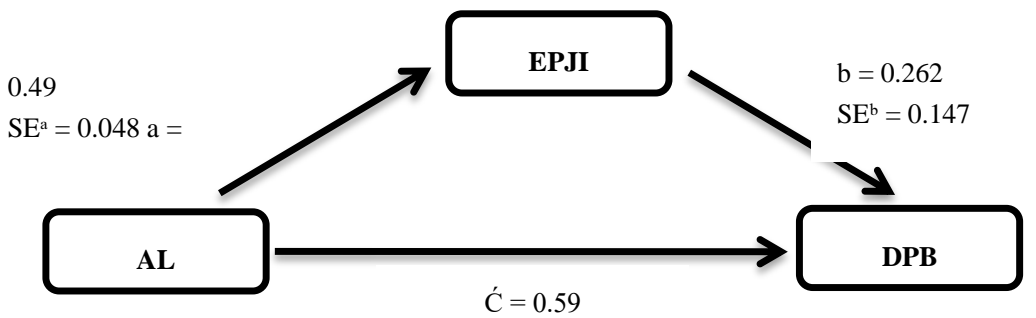

The direct and indirect effect

In the fig. 2, the values generated are from the regression run for the mediation of the present The value of $a$ represents the unstandardized coefficient beta of direct relation of independent variable AL with dependent variable EPJI i.e., 0.49. Whereas, the $b$ value represents the unstandardized coefficient beta of indirect relation of mediator EPJI with dependent variable DPB i.e., 0.262. The SEa represents the standard error of direct relation of independent variable $\mathrm{AL}$ with dependent variable EPJI i.e., 0.048. Whereas, the $\mathrm{SE}^{\mathrm{b}}$ represents the standard error of indirect relation of mediator EPJI with dependent variable DPB i.e., 0.147. The values are generated from the regression results of hypothesis 2 discussed in the present study. The Ć value represents the unstandardized 
coefficient beta of the direct relation of independent variable AL with dependent variable DPB when having a mediating effect of EPJI i.e., 0.59. The $\mathrm{C}$ value is equal to the value of standardizing coefficient beta in the regression analysis i.e., 0.717

Most importantly is the $\mathrm{z}$ value in the Sobel test, that if the $\mathrm{z}$ value is $\geq 1.96$ or $\leq-1.96$, then it means that the mediation exists (Sobel, 1982). For this the assumptions are taken into notice that;

$\mathrm{H}^{\circ}=(\mathrm{a})(\mathrm{b})=0 \rightarrow$ No mediation.

$\mathrm{H}^{1}=(\mathrm{a})(\mathrm{b}) \neq 0 \rightarrow$ There is a mediation.

For this;

$\mathbf{z}=(\mathbf{a})(\mathbf{b}) / \mathbf{S E}^{\mathrm{ab}}$

Where,

$\mathbf{S E}^{\mathrm{ab}}=\sqrt{ } \mathbf{b}^{2} \mathbf{S}^{\mathbf{2} 2}+\mathbf{a}^{2} \mathbf{S}^{\mathbf{b} 2}$

Putting the values in the equation;

$\mathrm{SE}^{\mathrm{ab}}=\sqrt{ }(0.262)^{2} \cdot(0.048)^{2}+(0.049)^{2}(0.147)^{2}$

$\mathrm{SE}^{\mathrm{ab}}=\sqrt{ }(0.0686)(0.0023)+(0.2401)(0.021)$

$\mathrm{SE}^{\mathrm{ab}}=\sqrt{ }(0.000157+0.0051)$

$\mathrm{SE}^{\mathrm{ab}}=\sqrt{ }(0.0052)$

$\mathrm{SE}^{\mathrm{ab}}=0.072$

Putting the value of $S E^{a b}$ in $z$ equation;

$\mathrm{z}=(\mathrm{a})(\mathrm{b}) / \mathrm{SE} \mathrm{E}^{\mathrm{ab}}$

$\mathrm{z}=0.128 / 0.072$

$\mathrm{z}=1.77$

Here, the value of $\mathrm{z}$ shows that mediation exists there. So according to the assumptions $\mathrm{H}^{\circ}$ is rejected here and $\mathrm{H}^{1}$ is accepted here because of $\mathrm{ab} \neq 0$. According to the test results, it is shown that the direct relation of autocratic leadership with disruptive political behavior if affected by an indirect relation of employee's perception of job insecurity.

\section{Preacher \& Hayes Mediation Test}

This is used to test the mediation and moderation effects of variables in the hypothetical model that either the mediation or moderation exists or not (Preacher \& Hayes, 2008). In the present study, this test is applied to mediation to check the direct and indirect effect of the constructs used in the present study model. See Fig. 3.

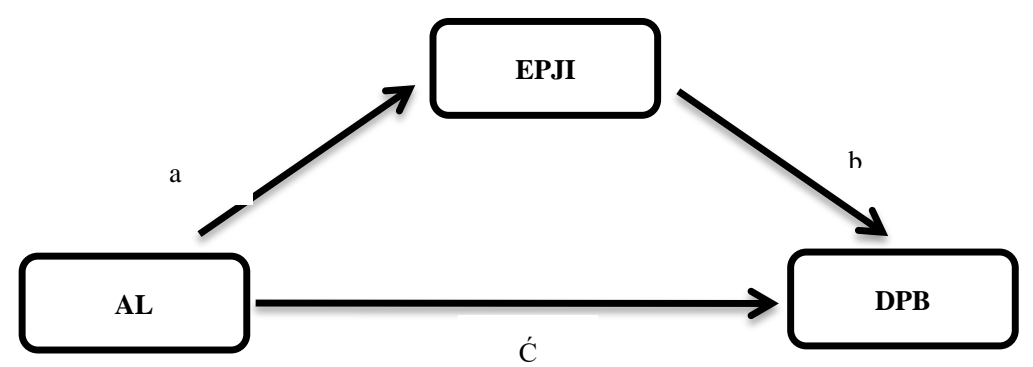

Direct \& indirect effect

The direct and indirect effect is clearly shown. As the EPJI is the mediator and the all an independent variable showing an effect on DPB as a dependent variable. According to Preacher and Hayes (2008), the IV is represented as X, DV is represented as Y and a mediator is represented as M. In the Preacher and Hayes test, the confidence level is set up to 95\% for more accuracy of results in the data. The LLCI (lower level of confidence interval) and ULCI (upper level of confidence interval) is mentioned. The difference between their values shows the effect of the variable in the model. The value of the effect must not be equal to zero. If the value is equal to zero then this will show that there is no mediation (Preacher \& Hayes, 2008).

The mediation is showing the significance of $90 \%$ which means that the mediation exists. Whereas, the tolerance 
value is 1.78 which is also acceptable. Taking the LLCI \& ULCI of the mediation, LLCI is showing a negative value whereas, ULCI is showing a positive value.

Table 14. Model summary of affrays test

\begin{tabular}{lcccccc}
\hline & Coefficient & SE & T & P & LLCI & ULCI \\
\hline Constant & .4355 & .5710 & .7627 & .4487 & -.7075 & 1.5785 \\
EPJI & .2617 & .1468 & 1.7832 & .0798 & -.0321 & .5555 \\
AL & .5905 & .0719 & 8.2132 & .0000 & .4466 & .7344 \\
\hline
\end{tabular}

\subsection{Direct \& Indirect Effect}

The direct and indirect effect is already been discussed above. In the test, the model explains well the direct and indirect effect of the variables with their effects.

Table 15. The direct effect of AL \& DPB

\begin{tabular}{lllllll}
\hline Model & Effect & SE & T & P & LLCI & ULCI \\
\hline AL & .5905 & .0719 & 8.2132 & .0000 & .4466 & .7344 \\
\hline Model & Effect & & Boot SE & Boot LLCI & Boot ULCI \\
\hline EPJI & .0147 & & .0221 & -.0083 & .0849 \\
\hline
\end{tabular}

The direct and indirect effect model, it shows that the direct effect of AL \& DPB. The value of LLCI is 0.4466 \& ULCI is 0.7344 values which show the effect value as 0.5905 with a high significance level. Whereas in the indirect effect model, LLCI is -0.0083 , and ULCI is 0.0849. According to Preacher and Hayes (2008), the difference between the values of LLCI and ULCI must not be equal to zero. The indirect effect of AL \& DPB shown in the table is 0.0147 . Taking the effect from the table shown above, the confidence interval is set to $95 \%$ due to which the positive and negative value came in the lower confidence interval. By taking the confidence interval of $90 \%$ and by taking the reference from the Sobel test, the mediation exists greater than $90 \%$ in the present study results. According to the present study, after doing the literature review, the study is been tested after collecting the data. For a collection of data, factor analysis is been used to reduce the items of the study which results in the respondents $248(\mathrm{n}=248)$. The demographics are filled from the respondents of the telecommunication sector of Lahore like; gender, age, experience, and designation. Various tests are applied on the data to check the correlation, validity \& reliability of the variables. To check the significance among the variables, regression analysis is run on the available data. The hypothesis is showing the significance among the variables. According to the regression analysis $\mathrm{H} 1(\mathrm{AL} \rightarrow \mathrm{DPB}), \mathrm{H} 2(\mathrm{AL} \rightarrow \mathrm{EPJI}) \& \mathrm{H} 3$ (AL $\rightarrow$ EPJI moderating effect of ASB) is showing the high significance. Whereas, the H4 (AL $\rightarrow$ EPJI $\rightarrow$ DPB) is showing the significance of $90 \%$ among the variables in regression, Sobel, and Preacher \& Hayes test analysis.

\section{Discussion}

The discussion includes the objectives, methodology, and study of the results found. According to the present study, the objective is to check the impact of an autocratic leader who opts an abusive behavior (to meet the organizational deadlines) on the attitudes and behaviors of an employee, which enhance the employee's perception of job insecurity resulting in the disruptive political behavior opted by an employee (to secure his/her job). For this, the present study conducted is an empirical study on which different tests are applied to check the authenticity of the variables in the culture of the Telecommunication sector of Lahore, Pakistan. Taking this into the context, all the variables are highly correlated and also showing the significant relationships among them.

According to the previous studies, which were conducted in various sectors and countries of the world, the present study is conducted in Pakistan taking the public and private telecommunication sector of Lahore as a sample. The present study fills the gap which is been discussed in Chapter 2 (Kiazad, Restubog, Zagenczyk, Kiewitz, \& Tang, 2010; Chan \& McAllister, 2014; Lebel, 2017). Taking the previous study into the context, while working in an autocratic cultured organization, sometimes when meeting the deadlines, the behavior of a boss leads the employee to opt different behaviors which are harmful for the organization (Chan \& McAllister, 2014), discussed a disruptive political behavior in the present study. Concerning the literature, the variable i.e., autocratic leadership and disruptive political behavior are highly correlated and significant $(r=0.56, p<0.01)$. So, according to the literature and the regression analysis results, hypothesis 1 is showing positive results and is 
accepted in the telecommunication sector of Pakistan.

Comparing hypothesis 2 and hypothesis 3 of the present study and the literature, literature discusses that an employee perceives a job insecurity while working in that kind of environment where the supervisor is directive and expects undeniable obedience (Cheng, Chou, Wu, Huang, \& Farh, 2004, p. 91) by maintaining a social gap between them. This type of insecurity inhibits while working under an autocratic leader in the organization who encourages his subordinates while threatening with punishments rather than encouraging with rewards (Bass \& Bass, 2008; Yukl, 2010). The results for hypothesis 2 proved that the literature is a piece of clear evidence for these behavioral patterns of an employee. The results show that autocratic leadership is positively \& highly correlated and highly significant with employee's perception of job insecurity $(r=0.49, \mathrm{p}<0.01)$. So, after the regression analysis, this proves that hypothesis 1 is showing positive results and according to the results, autocratic leadership is showing a positive impact on employee's perception of job insecurity.

Regarding hypothesis 3, literature also gave pieces of evidence relevant to autocratic leadership style and employee's perception of job insecurity with a moderating effect of abusive supervisory behavior. The autocratic leader is bound to rules and policies and expects to accomplish the tasks given by them (Malik, Saleem, \& Naeem, 2016) due to which, he expects undeniable obedience and encourage the sub-ordinates with threats and punishments (Bass \& Bass, 2008; Yukl, 2010). The literature discusses that it is a perception of an employee that how he/she is taking such abusiveness of a supervisor either positive or negative. Negative perception results in the perception of job insecurity (Loi, Lam, \& Chan, 2012). So when an employee is been victimized by an abusive behavior opted by an autocratic leader leads to an employee's perception of job insecurity, it is showing a positive moderating relationship of abusive supervisory behavior. This moderating variable is highly and positively correlated and also showing a high significance in the relation of the variables $(r=0.44, p<0.01)$. So, after the regression analysis result, the present study proved that hypothesis 3 is accepted, and comparing with literature, the autocratic leader when it becomes abusive shows a positive impact on employee's perception of job insecurity.

Discussing hypothesis 4 of autocratic leadership results in disruptive political behavior with a mediating effect of an employee's perception of job insecurity. The previous studies show that when an employee perceives insecurity regarding his job, this reduces the level of OCB (organizational citizenship behavior) of an employee (Reisel et al., 2010) and tend to react against the organization and the other individuals (Chan \& McAllister, 2014). This results in the adoption of such political behaviors which are discussed as disruptive political behaviors of an employee in the present study. Taking the present study results into the context, the mediating effect of employee's perception of job insecurity is positively highly correlated $(r=0.54)$ and also showing a significance of $90 \%$ in the variables. For mediation of the variables, regression analysis, Sobel test, and Preacher \& Hayes test is conducted on the present study. The results of all these analyses show that the mediation exists among the variables and employee's perception of job insecurity is showing a positive impact upon the behaviors of an employee to adopt disruptive political behaviors to secure his job.

\section{Conclusion \& Implications}

The brief review of the conclusion taken out of the findings and analysis of the generated hypothesis of a present empirical study. In addition to this, theoretical implications and the managerial implications taken out from the findings of the present study are also discussed in this chapter.

From an applicative point of view, the results are been analyzed and interpreted which shows a piece of evidence that according to literature, research gaps are discussed in the study above which is been fulfilled in the present study. The previous study discussed that the literature limits the studies regarding the different behaviors which an employee opt while working in an autocratic culture after experiencing an abusive behavior, adopt some behaviors for securing one's job (Lebel, 2017). The present study fulfills the gaps which explain that there are other behaviors also other than the safety behaviors of an employee working in an autocratic culture. The present study also contributes to the body of knowledge that other than constructive behaviors that an employee opt while perceiving his job insecure.

So, when there is an autocratic culture in the organization, it happens sometimes that to meet the deadlines, the supervisor when becomes abusive enhances the level of employee's perception of job insecurity which results in such behaviors that an employee opts for securing his job. These behaviors are said to be the negative behaviors of an employee which comes in the reaction after experiencing a harsh or abusive behavior from an autocratic leader (Tepper, 2000; Freeman et al., 2001, 2005; Chan \& McAllister, 2014). The results of the present study show that an autocratic leadership style is positively and significantly impacting the deviant behaviors of an employee said to be the disruptive political behaviors in the present study. 
Similarly, concerning this, the present study shows that the organization which inhibits the autocratic culture positively impact the employee's perception of job insecurity due to the reason that an employee always feels that in a situation of incapability of meeting the defined targets, a supervisor may react abusively and may punish him. So the present study is contributing the body of knowledge that the harsh reaction of an autocratic leader, may result in employee's perception of job insecurity and showing the positive and significant impact after analyzing the data. According to the gap identified from the previous studies, the present study is showing $90 \%$ significance among the mediating relation of employee's perception of job insecurity resulting in adoption of disruptive political behavior in which an employee opts for securing his job.

According to the present study, conducted in the public and private telecommunication sector of Pakistan, H1, $\mathrm{H} 2, \mathrm{H} 3$ is completely accepted and shows high significance after collecting and analyzing data. Whereas, the H4 is showing $90 \%$ significance. Taking this further theoretical and managerial implications are discussed in the study. According to the model of perceived organizational politics (Ferris, Ruth, \& Fandt, 1989), the literature limits the study by discussing the different behaviors expect the negative emotions which result in destructive outcomes (Lebel, 2017). The present study explains the negative behavior of employees named as disruptive political behavior of employees after perceiving one's job insecure while working in an autocratic leader who opts abusiveness sometimes to meet the deadlines. Taking this, the present empirical research is conducted in the telecommunication sector, to test the variables in the culture of Pakistan. So the findings of this study have provided the empirical support to newly build constructs with the moderating effect of the supervisor's abusiveness and mediating effect of employee's perception of job insecurity. The present study is conducted first time in the telecommunication sector of Pakistan with the discussed constructs and their relationship which gives a contribution to the body of knowledge.

Therefore, the study might be helpful for the managers of organizations that the use of authoritative power is good in the organizational culture of Pakistan. But the use of abusiveness by an authoritative leader sometimes affects the psychological well-being of an employee that it takes an employee to perceive his job insecure which ultimately leads to disruptive political behaviors. Regarding this, motivational training sessions can help the employees and the supervisor both so that both would be able to take the tasks before deadlines which would not affect the psychological well-being of an employee and the boss. Secondly, employees must be given that type of training that even working in an autocratic culture, their emotional exhaustion never leads to disruptive political behaviors e.g., in Pakistan Army autocratic leadership (Khan, 2012) exists but this never leads to disruptive political behaviors. Thirdly, the employees of the organization must be given some freedom of speech that if anybody in the organization is trying to create the environment of disruptive political behavior, the boss must be capable to handle the situation instead of being abusive.

The present study conducted on demographics discussed in chapters $4 \& 5$ in the public and private telecommunication sector of Pakistan based on a cross-sectional survey method which may be considered as one of the limitations. Concerning this, taking other perspectives, the autocratic leadership trait of a boss not always flow towards a negative emotional state but also have positive outcomes. The research limits itself to the negative behavior of a leader which flows the study towards impoliteness which again results in negative emotion of an employee. Taking this viewpoint, the research also limits its study to a single negative behavior of an employee i.e., perception of job insecurity. More negative behaviors and positive behaviors of an individual working in the organization can contribute to the literature. Moreover, the study limits itself to disruptive political behaviors. There could be more behaviors that came under disruptive political behaviors which would explain the research further and could contribute to the body of knowledge. The researcher encourages the future directions to replicate the findings of the study regarding the proposed constructs and also to confirm the hypothesis in different job settings, different organizational cultures with different demographics in cross-sectional or longitudinal survey method. Disruptive political behavior is a new construct. So, the study expects the reverse effects of an employee's disruptive political behaviors on job insecurity, supervisor's abusiveness, and on autocratic leadership that after adopting political behaviors, what would be the reaction of an autocratic leader by taking given one's insecure job. More moderating constructs than abusiveness and mediating constructs than employee's perception of job insecurity could be studied further for more contribution to the study. Various types of political behaviors can be studied under disruptive political behaviors which can come under negative emotional reaction and various positive political behaviors can come as the positive emotional reactions of an employee which would enhance the knowledge.

\section{References}

Abbas, M., Raja, U., Darr, W., \& Bouckenooghe, D. (2014). Combined effects of perceived politics and psychological capital on job satisfaction, turnover intentions, and performance. Journal of Management, 
40(7), 1813-1830. https://doi.org/10.1177/0149206312455243

Ashford, S. J., Lee, C., \& Bobko, P. (1989). Content, cause, and consequences of job insecurity: A theory-based measure and substantive test. Academy of Management Journal, 32(4), 803-829. https://doi.org/10.2307/256569

Baillien, E., \& De Witte, H. (2009). Why is organizational change related to workplace bullying? Role conflict and job insecurity as mediators. Economic and Industrial Democracy, 30(3), 348-371. https://doi.org/10.1177/0143831X09336557

Bhattacherjee, A. (2012). Social science research: principles, methods, and practices.

Bhatti, N., Maitlo, G. M., Shaikh, N., Hashmi, M. A., \& Shaikh, F. M. (2012). The impact of autocratic and democratic leadership style on job satisfaction. International Business Research, 5(2), 192. https://doi.org/10.5539/ibr.v5n2p192

Burnham, P., Lutz, K. G., Grant, W., \& Layton-Henry, Z. (2008). Research methods in politics. Palgrave Macmillan. https://doi.org/10.1007/978-0-230-36556-8

Chang, C. H., Rosen, C. C., \& Levy, P. E. (2009). The relationship between perceptions of organizational politics and employee attitudes, strain, and behavior: A meta-analytic examination. Academy of Management Journal, 52(4), 779-801. https://doi.org/10.5465/amj.2009.43670894

Chang, C. H., Rosen, C. C., Siemieniec, G. M., \& Johnson, R. E. (2012). Perceptions of organizational politics and employee citizenship behaviors: Conscientiousness and self-monitoring as moderators. Journal of Business and Psychology, 27(4), 395-406. https://doi.org/10.1007/s10869-012-9257-6

Cheng, B. S., Chou, L. F., Wu, T. Y., Huang, M. P., \& Farh, J. L. (2004). Paternalistic leadership and subordinate responses: Establishing a leadership model in Chinese organizations. Asian Journal of Social Psychology, 7(1), 89-117. https://doi.org/10.1111/j.1467-839X.2004.00137.x

De Spiegelaere, S., Van Gyes, G., De Witte, H., Niesen, W., \& Van Hootegem, G. (2014). On the relation of job insecurity, job autonomy, innovative work behaviour and the mediating effect of work engagement. Creativity and Innovation Management, 23(3), 318-330. https://doi.org/10.1111/caim.12079

De Witte, H., De Cuyper, N., Vander Elst, T., Vanbelle, E., \& Niesen, W. (2012). Job insecurity: Review of the literature and a summary of recent studies from Belgium. Romanian Journal of Applied Psychology, 14(1), 11-17.

Ferris, G. R., \& Kacmar, K. M. (1992). Perceptions of organizational politics. Journal of Management, 18(1), 93-116. https://doi.org/10.1177/014920639201800107

Gandz, J., \& Murray, V. V. (1980). The experience of workplace politics. Academy of Management Journal, 23(2), 237-251. https://doi.org/10.2307/255429

Gkorezis, P., Petridou, E., \& Krouklidou, T. (2015). The detrimental effect of machiavellian leadership on employees' emotional exhaustion: Organizational cynicism as a mediator. Europe's Journal of Psychology, 11(4), 619. https://doi.org/10.5964/ejop.v11i4.988

Henle, C. A., \& Gross, M. A. (2014). What have I done to deserve this? Effects of employee personality and emotion on abusive supervision. Journal of Business Ethics, 122(3), 461-474. https://doi.org/10.1007/s10551-013-1771-6

Jogulu, U. D., \& Wood, G. J. (2008). A cross-cultural study into peer evaluations of women's leadership effectiveness. Leadership \& Organization Development Journal, 29(7), 600-616. https://doi.org/10.1108/01437730810906344

Kacmar, K. M., \& Ferris, G. R. (1991). Perceptions of organizational politics scale (POPS): Development and construct validation. Educational and Psychological Measurement, 51(1), 193-205. https://doi.org/10.1177/0013164491511019

Kacmar, K. M., Tillman, C. J., Harris, K. J., \& Whitman, M. V. (2015). Perceptions of Ethical Leadership as a Mediator of the Relationship between Abusive Supervision and Work Behaviors. Journal of Behavioral and Applied Management, 16(1), 2.

Khan, S. (2012). The military and economic development in Pakistan. Political Economy Research Institute, University of Massachusetts working paper series, 291.

Khan, S. A. (2012). Binding constraints: The role of the army in Pakistan's economic under-development. 
Kiazad, K., Restubog, S. L. D., Zagenczyk, T. J., Kiewitz, C., \& Tang, R. L. (2010). In pursuit of power: The role of authoritarian leadership in the relationship between supervisors' Machiavellianism and subordinates' perceptions of abusive supervisory behavior. Journal of Research in Personality, 44(4), 512-519. https://doi.org/10.1016/j.jrp.2010.06.004

Kline, R. B. (2010). Principles and practice of structural equation modeling (3rd ed.). New York, New York: Guilford Press.

Lebel, R. D. (2017). Moving beyond fight and flight: A contingent model of how the emotional regulation of anger and fear sparks proactivity. Academy of Management Review, 42(2), 190-206. https://doi.org/10.5465/amr.2014.0368

Lewin, K. (2013). Principles of topological psychology. Read Books Ltd.

Lewin, K., Lippitt, R., \& White, R. K. (1939). Patterns of aggressive behavior in experimentally created "social

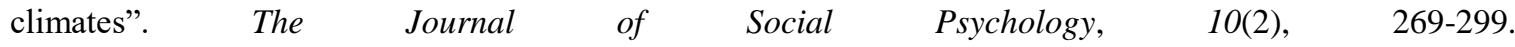
https://doi.org/10.1080/00224545.1939.9713366

Lincoln, Y. S., Lynham, S. A., \& Guba, E. G. (2011). Paradigmatic controversies, contradictions, and emerging confluences, revisited. The Sage Handbook of Qualitative Research, 4, 97-128.

Loi, R., Lam, L. W., \& Chan, K. W. (2012). Coping with job insecurity: The role of procedural justice, ethical leadership and power distance orientation. Journal of Business Ethics, 108(3), 361-372. https://doi.org/10.1007/s10551-011-1095-3

Malik, S. Z., Saleem, M., \& Naeem, R. (2016). Effect of leadership styles on organizational citizenship behaviour in employees of telecom sector in Pakistan. Pakistan Economic and Social Review, 54(2), 385.

Ojokuku, R. M., Odetayo, T. A., \& Sajuyigbe, A. S. (2012). Impact of leadership style on organizational performance: a case study of Nigerian banks. American Journal of Business and Management, 1(4), 202-207. https://doi.org/10.11634/216796061706212

Pienaar, J., \& De Witte, H. (2016). Work locus of control and sense of coherence as antecedents of job insecurity. South African Journal of Business Management, 47(3), 35-43. https://doi.org/10.4102/sajbm.v47i3.66

Preacher, K. J., \& Hayes, A. F. (2008). Assessing mediation in communication research. The Sage Sourcebook of Advanced Data Analysis Methods for Communication Research, 13-54. https://doi.org/10.4135/9781452272054.n2

Preedy, V. R., \& Watson, R. R. (2009) Handbook of Disease Burdens and Quality of Life Measures. New York: Springer. https://doi.org/10.1007/978-0-387-78665-0

Probst, T. M., \& Brubaker, T. L. (2001). The effects of job insecurity on employee safety outcomes: cross-sectional and longitudinal explorations. Journal of Occupational Health Psychology, 6(2), 139. https://doi.org/10.1037/1076-8998.6.2.139

Rast III, D. E., Hogg, M. A., \& Giessner, S. R. (2013). Self-uncertainty and support for autocratic leadership. Self and Identity, 12(6), 635-649. https://doi.org/10.1080/15298868.2012.718864

Scandura, T. A., \& Williams, E. A. (2000). Research methodology in management: Current practices, trends, and implications for future research. Academy of Management Journal, 43(6), 1248-1264. https://doi.org/10.2307/1556348

Sobel, M. E. (1982). Asymptotic confidence intervals for indirect effects in structural equation models. Sociological methodology, 13, 290-312. https://doi.org/10.2307/270723

Spain, S. M., Harms, P., \& LeBreton, J. M. (2014). The dark side of personality at work. Journal of Organizational Behavior, 35(S1), S41-S60. https://doi.org/10.1002/job.1894

Sultan, S., Kanwal, F., \& Gul, S. (2015). Factors of Perceived Organizational Politics: An Analysis of What Contributes the Most? Pakistan Journal of Commerce and Social Sciences, 9(3), 999-1011.

Sverke, M., Hellgren, J., \& Näswall, K. (2002). No security: A meta-analysis and review of job insecurity and its $\begin{array}{llllll}\text { consequences. Journal of Occupational Health Psychology, } & \text { 7(3), } 242 .\end{array}$ https://doi.org/10.1037/1076-8998.7.3.242

Vetting, T. S. (2010). Job insecurity, turnover intention and psychological distress: The mediating effect of job satisfaction and trust in management.

Vigoda-Gadot, E., \& Talmud, I. (2010). Organizational politics and job outcomes: The moderating effect of trust 
and social support. Journal of Applied Social Psychology, 40(11), 2829-2861. https://doi.org/10.1111/j.1559-1816.2010.00683.x

Wahyuni, D. (2012). The research design maze: Understanding paradigms, cases, methods and methodologies.

Wamsley, G. L., \& Zald, M. N. (1973). The political economy of public organizations. Public Administration Review, 62-73. https://doi.org/10.2307/974786

Warner, R. M. (2012). Applied statistics: from bivariate through multivariate techniques: From bivariate through multivariate techniques. Sage.

Wilson, J. (2010). Essentials of Business Research: A Guide to Doing Your Research Project. SAGE Publications.

Witte, H. D. (1999). Job insecurity and psychological well-being: Review of the literature and exploration of some unresolved issues. European Journal of work and Organizational psychology, 8(2), 155-177. https://doi.org/10.1080/135943299398302

Zahra, S. A. (1985). Background and work experience correlates of the ethics and effect of organizational politics. Journal of Business Ethics, 4(5), 419-423. https://doi.org/10.1007/BF02388597

\section{Copyrights}

Copyright for this article is retained by the author(s), with first publication rights granted to the journal.

This is an open-access article distributed under the terms and conditions of the Creative Commons Attribution license (http://creativecommons.org/licenses/by/4.0/). 